\title{
Effects of circuit training as alternative to usual physiotherapy after stroke: randomised controlled trial
}

\author{
(c) $(1) \Theta$ OPEN ACCESS
}

\author{
Ingrid G L van de Port assistant professor ${ }^{1}$, Lotte E G Wevers PhD student ${ }^{1}$, Eline Lindeman \\ professor $^{1}$, Gert Kwakkel professor ${ }^{12}$
}

${ }^{1}$ Rudolf Magnus Institute of Neuroscience and Centre of Excellence for Rehabilitation Medicine, University Medical Centre Utrecht and Rehabilitation Centre De Hoogstraat, Utrecht Rembrandtkade 10, 3583 TM Utrecht, Netherlands; ${ }^{2}$ Department of Rehabilitation Medicine, Research Institute MOVE, VU University Medical Centre, De Boelelaan 1117, 1081 HV Amsterdam, Netherlands

\begin{abstract}
Objective To analyse the effect of task oriented circuit training compared with usual physiotherapy in terms of self reported walking competency for patients with stroke discharged from a rehabilitation centre to their own home.

Design Randomised controlled trial with follow-up to 24 weeks.

Setting Multicentre trial in nine outpatient rehabilitation centres in the Netherlands

Participants Patients with stroke who were able to walk a minimum of $10 \mathrm{~m}$ without physical assistance and were discharged from inpatient rehabilitation to an outpatient rehabilitation clinic. Patients were randomly allocated to circuit training or usual physiotherapy, after stratification by rehabilitation centre, with an online randomisation procedure.

Intervention Patients in the intervention group received circuit training in 90 minute sessions twice a week for 12 weeks. The training included eight different workstations in a gym and was intended to improve performance in tasks relating to walking competency. The control group received usual outpatient physiotherapy.
\end{abstract}

Main outcome measures The primary outcome was the mobility domain of the stroke impact scale (SIS, version 3.0). Secondary outcomes were standing balance, self reported abilities, gait speed, walking distance, stair climbing, instrumental activities of daily living, fatigue, anxiety, and depression. Differences between groups were analysed according to the intention to treat principle. All outcomes were assessed by blinded observers in a repeated measurement design lasting 24 weeks.

Results 126 patients were included in the circuit training group and 124 in the usual care group (control), with data from 125 and 117, respectively, available for analysis. One patient from the circuit training group and seven from the control group dropped out. Circuit training was a safe intervention, and no serious adverse events were reported. There were no significant differences between groups for the stroke impact scale mobility domain ( $\beta=0.05$ (SE 0.68), $P=0.943$ ) at 12 weeks. Circuit training was associated with significantly higher scores in terms of gait speed $(0.09 \mathrm{~m} / \mathrm{s}$ (SE 0.02), $\mathrm{P}<0.001)$, walking distance $(20.0 \mathrm{~m}$
(SE 7.4), $P=0.007$ ), and modified stairs test (-1.6 s (SE 0.7), $P=0.015$ ). There were no significant differences between groups for the other secondary outcomes, except for the leisure domain of the Nottingham extended activities of daily living and the memory and thinking domain of the stroke impact scale. With the exception of gait speed $(-0.04 \mathrm{~m} / \mathrm{s}$ (SE 0.02), $P=0.040$ ), there were no significant differences between groups at follow-up.

Conclusion Task oriented circuit training can safely replace usual physiotherapy for patients with stroke who are discharged from inpatient rehabilitation to the community and need further training in gait and gait related activities as an outpatient.

Trial registration Dutch Trial Register (NTR1534).

\section{Introduction}

An estimated $25-74 \%$ of the 50 million stroke survivors worldwide require some assistance or are fully dependent on care givers for activities of daily living after stroke. ${ }^{1}$ The activity with the greatest impact on independency in activities of daily living is walking, a skill initially lost by as many as $80 \%$ of patients. ${ }^{2}$ Self reported mobility problems are the most common unmet long term clinical needs after stroke. ${ }^{3}$ Next to medical management after acute stroke to prevent further cerebral damage, stroke rehabilitation is used to achieve better recovery in the first months after stroke and reduce disability during the subsequent years. ${ }^{4}$

Task specific training targeting goals relevant to patients' needs, as well as high intensity practice with sufficient repetitions, are the main principles determining effective stroke rehabilitation care. ${ }^{4}$ Several meta-analyses have shown that task oriented exercises focusing on balance control, transfers, gait, and gait related activities such as climbing stairs are effective, particularly when applied within the first six months after stroke. $^{4-6}$ 
Recently, two independent meta-analyses showed that group training with a series of workstations (known as circuit training) offers benefits in terms of gait speed, walking distance, stair climbing, and transfers, compared with other commonly used forms of physiotherapy. ${ }^{78}$ There were no adverse effects in terms of falls or other complications related to exertion compared with physiotherapy. Apart from group dynamics and a focus on progressive repetitive practice of functional tasks, one of the key components of task oriented circuit class training is that the treatment is provided in a group setting with more than two participants per therapist, resulting in a lower ratio of staff to patients. ${ }^{78}$ In addition, most studies were conducted in patients with chronic stroke, and therefore we need studies into the effectiveness for people within the first six months after stroke. $^{8}$

We investigated the safety and effects of task oriented circuit training as an alternative to usual physiotherapy provided during outpatient treatment at a rehabilitation centre to improve walking. Usual physiotherapy was provided in individually tailored, face to face treatment sessions. We hypothesised that circuit training would be a safe treatment strategy that is superior to usual physiotherapy in terms of self reported competency in walking for patients discharged from a rehabilitation centre to their own home over a 24 week time period.

\section{Methods}

We used a stratified, multicentre single blinded randomised controlled trial with repeated measurements to investigate the effects of the task oriented circuit training programme. Nine rehabilitation centres in the Netherlands participated in the study. Full details of this trial, called FIT-Stroke, have been reported elsewhere. ${ }^{9}$ Three trained research assistants (LW, HK, LK), who were blinded to treatment allocation, measured all outcomes before randomisation at baseline and after 12 and 24 weeks in face to face meetings at the patient's own home or at the rehabilitation centre. The same assessor tested participants each time. The mobility domain of the stroke impact scale (the primary outcome) and the other domains of the scale were also measured at six and 18 weeks by telephone interview and included for statistical analysis. Participants were stratified by rehabilitation centre, and randomisation took place using an "online" minimisation procedure. ${ }^{10}$

\section{Participants}

We included all patients with stroke who had completed an inpatient rehabilitation period as soon as they were able to start outpatient rehabilitation in one of the nine participating centres. For inclusion, eligible patients had to have had a verified stroke according to the WHO definition; be able to walk a minimum of $10 \mathrm{~m}$ without physical assistance (functional ambulation categories $\geq 3$ ); be discharged home from a rehabilitation centre; need to continue physiotherapy during outpatient care to improve walking competency or physical condition, or both; and be able to give informed consent and be motivated to participate in a 12 week intensive programme of physiotherapy. Patients were excluded if they had cognitive deficits as evaluated by the mini-mental state examination ( $<24$ points), were unable to communicate $(<4$ points on the Utrechts Communicatie Onderzoek, UCO), or lived more than $30 \mathrm{~km}$ from the rehabilitation centre.

\section{Interventions}

Intervention group - Patients assigned to the intervention group received a 90 minute, graded task oriented circuit training programme twice a week over a 12 week period ( 24 sessions). The training included eight different workstations, intended to improve meaningful tasks relating to walking competency. ${ }^{9}$ At each workstation, participants worked together in pairs: while one participant performed the task for three minutes, the other observed their performance. After three minutes of practice or observation, they switched roles. After six minutes at the workstation, each pair had one minute to go to the next workstation. Each participant's performance (such as counts) was recorded in a training log, which was used as a feedback and motivational tool during the next sessions. Motivational music was played in the background during the entire training session. The total FIT-Stroke programme included four stages: warming up (5 minutes), circuit training (60 minutes), evaluation and a short break (10 minutes), and group game (15 minutes). The physiotherapist and sports therapists who conducted the programme were trained on a one day course before the FIT-Stroke trial started. The staff recorded patients' attendance at the sessions and adverse events (such as falls, heart problems) during the intervention. Serious adverse events were defined as any fall or other adverse event related to treatment that required a hospital or GP visit. Serious adverse events were reported to the medical ethics committee.

Control group-Patients allocated to the control group received usual outpatient physiotherapy, mainly one to one treatments tailored to the patient with a physiotherapist who had not been on the circuit training course at one of the participating rehabilitation centres. Sessions designed to improve control of standing balance, physical condition, and walking competency were provided according to Dutch physiotherapy guidelines. ${ }^{11}$ There were no additional restrictions with respect to content, time, or duration of the physiotherapy.

\section{Outcomes}

Primary outcome measure-This was the mobility domain of the stroke impact scale. This scale is a self reported, stroke specific, valid, reliable, and responsive measure that includes 59 items and assesses eight domains related to activities and participation. ${ }^{12} 13$ The mobility domain of the scale includes nine questions about a patient's perceived competency to keep his or her balance, to transfer, to walk indoors and climb stairs, to get in and out of a car, and to move about in the community. Total scores range from 0 to 100 , higher scores indicating better mobility. The stroke impact scale was administered at baseline and at six, 12, 18, and 24 weeks after randomisation. At six and 18 weeks, this was carried out in a semistructured telephone interview. We included 220 patients to give enough power to detect a clinically relevant difference of 5 points (about 11\%) on the mobility domain of the stroke impact scale in favour of the experimental group. ${ }^{9}$

Secondary outcome measures - Secondary outcomes included other domains of the stroke impact scale (version 3.0), the Rivermead mobility index (RMI), the falls efficacy scale (FES), the Nottingham extended activities of daily living (NEADL), the hospital anxiety and depression scale (HADS), and the fatigue severity scale (FSS). Other secondary outcomes were performance tests-namely, the Motricity index (MI-arm and MI-leg), functional ambulation categories, six minute walk test, ${ }^{14}$ five metre comfortable walking speed test, timed balance test, timed up and go, modified stairs test, and letter cancellation task. Extensive descriptions (including psychometric properties and references) of all secondary outcomes are available elsewhere. ${ }^{9}$ All secondary outcomes (questionnaires and performance tests) were measured at baseline and at 12 and 24 weeks after randomisation. The physiotherapist recorded adverse 
events, including falls and heart problems, in the patients' diary. Serious adverse events were defined as falls and incidents related to equipment failure or incidents related to treatment leading to injury requiring a hospital or GP visit. Serious adverse events were reported to the medical ethics committee. In addition, patients were asked to record all medical events such as falls and hospital visits in a weekly dairy kept for at least 12 weeks.

\section{Data analysis}

We tested for differences in baseline values between circuit training and usual care groups with Fisher's exact test or $\chi^{2}$ test for nominal outcomes, the Mann-Whitney U test for ordinal scale outcomes, and Student's $t$ test for independent groups, assuming equal variances for interval or ratio scale outcomes. Subsequently, we used random coefficients analysis (MLwIN, version 2.23, Centre for Multilevel Modeling, University of Bristol) to evaluate differences in overall effects between the groups for the 12 week intervention phase and the follow-up phase. We included time, group, and the interaction between group and time in the multilevel regression model. In addition, we added the baseline value of the dependent variable, as well as possible significant covariates at baseline, to the model. ${ }^{15}$ All random coefficient analyses were performed on all included patients, including those with incomplete sets of data. We also used different longitudinal imputation forms, including last value carried forward, for intention to treat analyses.

Subsequently, we calculated regression coefficients for the effects of circuit training compared with usual physiotherapy as $\beta$ values and standard errors favouring or disfavouring the circuit training group compared with usual care and used the Wald test to obtain a probability value for each regression coefficient.

We used Fisher's exact test to test for differences in the number of adverse events, including falls during the intervention phase, as well as differences in the proportion of patients who showed a meaningful improvement of $54 \mathrm{~m}$ or more on the six minute walk test, and Student's $t$ tests for independent groups, assuming equal variances to test the overall amount of treatment received in the circuit training or usual care group and differences in the ratio of staff to patients. All hypotheses were tested two sided, with a critical value of $<0.05$.

\section{Results}

Between June 2008 and December 2010, 250 patients were randomly assigned to circuit training $(\mathrm{n}=126)$ or usual care $(n=124)$ (figure $\Downarrow$ ). This total of 250 patients represents nearly $26 \%$ of the total population of stroke patients who followed an outpatient rehabilitation programme in the participating rehabilitation centres in this period. About two thirds $(n=662)$ of discharged patients could not participate in the study. About a third of these patients were too able to qualify for 24 sessions of 90 minutes physiotherapy in an outpatient setting, whereas another third of the patients were unable to walk independently for $10 \mathrm{~m}$, had disabling comorbidity, were not able to communicate, and/or were discharged to a nursing home. For the 309 patients who fulfilled the inclusion criteria, reasons for not participating included that they preferred to follow their outpatient programme in their own community, were not available for the subsequent 12 weeks, or were not interested in participating in a study $(\mathrm{n}=59)$. Of the 250 included patients, one patient in the circuit training group and seven in the usual care group were excluded from the analysis. Reasons were withdrawal from participation $(n=3)$, death from cancer $(n=2)$, and recurrent stroke $(n=2)$, while one patient missed the 12 week assessment visit because of change of address. No patients were lost to follow-up after 12 weeks. The patients attended an average of $83 \%$ of the 24 sessions, corresponding to an average treatment time of 1793 minutes per patient over 12 weeks. Four patients allocated to the intervention group did not attend the circuit training sessions.

The circuit training group received 4461 treatment sessions compared with 4378 for the usual care group. The average treatment time per session was 72 (SD 39) minutes for the intervention group compared with 34 (SD 10) minutes for the control group $(\mathrm{P}<0.05)$. As the intervention group received the treatment in groups, this longer treatment time could be provided with a lower ratio of staff to patients. The ratio was $0.56(1: 1.8)$ for the circuit training group and $0.78(1: 1.3)$ for the usual care group.

Twenty nine falls were reported in the circuit training group and 26 in the usual physiotherapy group $(\mathrm{P}=0.93)$. Two serious adverse events were reported in the circuit training group: one participant fell and consulted a GP and one patient experienced arrhythmias during one session. She discontinued the training session but was able to continue the programme after a medical check up.

Comparison between the observers' guesses about allocation (circuit training or control) and actual allocation showed that 76 of 126 predictions were correct in the control group and 79 of 127 in the experimental group, resulting in a Cohen's $\kappa$ of 0.24 . This suggests that the blinding procedure was successful. Table $1 \Downarrow$ shows the baseline characteristics of patients for the primary and secondary outcomes.

\section{Outcomes}

Table $2 \Downarrow$ shows the $\beta$ (SE) and $\mathrm{P}$ values for the effects within groups of time (baseline to 24 weeks) and effects between groups for the intervention phase (baseline to 12 weeks) and follow-up phase (12 to 24 weeks) of primary and secondary outcome measures. We found no significant differences between groups for mobility on the stroke impact scale (-0.05 (SE 0.68), $\mathrm{P}=0.94)$. Significant effects between groups in favour of the circuit training group were found for the five metre comfortable walking speed test $(0.09 \mathrm{~m} / \mathrm{s}(0.02), \mathrm{P}<0.001)$, the six minute walk test (20.0 m (7.4), $\mathrm{P}=0.007)$, and the modified stairs test $(-1.61 \mathrm{~s}(0.66), \mathrm{P}=0.015)$ during the intervention phase. Fifty eight out of $116(50 \%)$ patients in the usual physiotherapy group and 76 out of the $125(61 \%)$ in the circuit training group showed a clinically meaningful change beyond 50 metres on the six minute walk test $(\mathrm{P}=0.06)$.

There were significant effects between groups favouring the usual care group for the memory and thinking domain of the stroke impact scale $(\beta=-1.61(0.71), P=0.024)$ and the leisure domain of the Nottingham extended activities of daily living scale $(\beta=-0.74(0.37), P=0.043)$ (table $2 \Downarrow)$. There were no significant differences between groups for the other secondary outcomes. Nor were there significant differences between groups during the follow-up phase for any of the variables, except for the five metre comfortable walking speed test $(-0.04(0.02)$, $\mathrm{P}=0.040$.

\section{Discussion}

Task oriented circuit training in patients with mild to moderate disability after stroke is safe and as effective as an individually tailored face to face treatment in the first six months after stroke. The present study stems from the recommendations of the American Heart Association, issued to promote the investigation 
of innovative methods to increase duration of practice with minimum use of resources. ${ }^{16} \mathrm{We}$ found that circuit training was not superior to usual care in terms of self reported mobility according to the mobility domain of the stroke impact scale. This negative result might have been caused by a small impact of circuit training on perceived gait performance and might also relate to ceiling effects of the stroke impact scale, probably because of the relatively high baseline scores in patients who were able to walk for $10 \mathrm{~m}$ without assistance at baseline.

\section{Effects on secondary outcomes}

In contrast to patients' self reported mobility, the circuit training proved more effective in terms of walking speed, stair walking, and walking distance, though differences were small: $9 \mathrm{~cm} / \mathrm{s}$ for walking speed and $20 \mathrm{~m}$ for walking distance, respectively. These differences were below the reported smallest detectable differences of $0.16 \mathrm{~m} / \mathrm{s}$ for the comfortable $10 \mathrm{~m}$ walking speed test ${ }^{17}{ }^{18}$ and $54 \mathrm{~m}$ for the six minute walk test. ${ }^{19}$ Although the differences were small, they were within the $95 \%$ confidence intervals for overall effect sizes reported in the meta-analyses by Wevers et $\mathrm{al}^{7}$ and English and Hillier. ${ }^{8}$ Apparently, the gains in walking speed we found are not enough to be reflected in improved walking capacity in the community. ${ }^{20}$ Also the difference in the proportion of patients (about 10\%) who had a clinically meaningful improvement on the six minute walk test was not significant. We had also hypothesised that there would be significant gains in patients' self reported competency to walk and transfer according to the stroke impact scale, the Rivermead mobility index, and their ability to walk in the community as measured with the mobility domain of the Nottingham extended activities of daily living scale. Our trial, however, yielded no significant differences for these outcomes, which further supports the task and context specific nature of exercise training and suggests that small gains in walking speed and walking distance are insufficient to result in significant improvements in patients' perception of gait performance. Nor can they be generalised to improvements in patients' ability to walk outdoors. The latter finding is in line with the inconclusive findings of previous studies regarding the relation between gait speed and community ambulation. ${ }^{21-23}$ Despite the small effects of the circuit training on gait speed and distance, the covariate of time (baseline to 24 weeks) was significant for almost all primary and secondary outcomes, except the stroke impact scale's domains of mood and emotions, the fatigue severity scale, the hospital anxiety and depression scale, time to accomplish the letter cancellation task, omissions on the letter cancellation task, and the timed balance test. This suggests that patients continue to improve their body functions, activities, and participation after discharge from a rehabilitation centre, irrespective of treatment type. The significant effect of time alone could reflect spontaneous neurological recovery, which might be considerable up to 12 weeks after stroke, ${ }^{24}$ as almost half of our patients were discharged within three months after stroke.

In designing the trial we also assumed that circuit training might help treat fatigue and depression in patients after stroke. Several studies have suggested that physical training has a positive effect on non-physical outcomes such as fatigue and depression in healthy people and patients. ${ }^{25}{ }^{26}$ In our study, however, we found no significant favourable effects for these outcomes, possibly because our patients showed low average levels of depression and fatigue at baseline. ${ }^{9}$ Future studies are needed in which circuit class training is targeted towards patients with fatigue or depression, or both.
Outcomes of the FIT-Stroke trial are important for the healthcare system as most patients with stroke discharged from a rehabilitation setting still require physiotherapy. Our trial shows that circuit training is a safe and feasible treatment with relatively high compliance rates and no serious adverse events.

\section{Strengths and limitations}

The present study also had some limitations. Firstly, although the trial was well powered, including 250 patients with few drop-outs, we found significant baseline differences in favour of the circuit training group for a few secondary outcomes. All analyses, however, were adjusted for these covariates at baseline. A second limitation is that we were able to recruit only a quarter of all patients who were discharged from one of the participating rehabilitation centres. These centres receive about $10 \%$ of all patients with stroke discharged from hospitals in the Netherlands. About a third of all patients discharged from these rehabilitation centres showed no or insufficient problems with walking and another third were too ill to be included in the present study. It should therefore be emphasised that patients with only mild to moderate stroke were selected, which limits the generalisability of our trial. A third limitation is that the combination of workstations in FIT-Stroke represents an arbitrary selection. Our workstations were selected for safety, clinical relevance in terms of activities, simplicity of execution, and feasibility, without additional costs to the physiotherapy department. ${ }^{97}$ Hence, it remains unclear whether a different combination of workstations would have resulted in other outcomes. In our opinion, the workstations for task oriented circuit training should at least be task specific, intensive, and graded in time.

Another important aspect of the task oriented circuit training is that it is offered in groups ranging from two to eight patients, suggesting that it is a cost effective treatment after stroke by lowering ratios of staff to patients. Our meta-analyses ${ }^{7}$ and the experience gained in the FIT-Stroke trial, as well as a recent Cochrane review, ${ }^{8}$ suggest that a ratio of 1:3 (that is, one staff member for three clients) is feasible in circuit training. ${ }^{8}$ When training is done in pairs, as in the FIT-Stroke study, an even higher ratio can be achieved. The direct and indirect cost benefits of using circuit training as an alternative to usual physiotherapy will be investigated separately in the FIT-Stroke programme.

\section{Conclusions and policy implications}

In these patients with mild to moderate disability after stroke, task oriented circuit training was safe and as effective as an individually tailored face to face treatment in the first six months after stroke. The lower ratio of staff to patients suggests that circuit training can be cheaper and a valuable treatment to intensify physiotherapy for patients with stroke. Further cost benefit analysis is required, and additional trials in different (sub)acute and chronic settings are needed to identify which patients might do better with each approach.

We thank the staff and patients of the participating rehabilitation centres: De Hoogstraat, Utrecht; Heliomare, Wijk aan Zee; Rijnlands Revalidatiecentrum, Leiden; Sophia Revalidatie, Den Haag; Stichting Revalidatie Breda, Breda; Via Reva/Kastanjehof, Apeldoorn; Roessingh, Enschede; De Trappenberg, Huizen; and Vogellanden, Zwolle. We also thank the Dutch Institute of Allied Health Care for their cooperation in training the physiotherapists and sports therapists and Hanneke Roelse and Lenneke van Kats who collected much of the data.

Contributors: GK and IGLvdP developed the idea and procured funding for the study. GK had the final responsibility of the FIT-Stroke 


\section{What is already known on this topic}

In patients with stroke, group circuit training is a safe and has good results in terms of walking distance and walking speed

Most previous trials were conducted in patients with chronic stroke, were small, and failed to follow-up adequately

\section{What this study adds}

Task oriented circuit training started in the first six months is as effective as individually tailored physiotherapy for patients with moderate to mild stroke

Circuit training could replace usual physiotherapy, allowing patients to exercise more intensively with a lower ratio of staff to patients Small task specific treatment effects favouring circuit training were found for walking distance, walking speed, and stair walking, though the differences between groups were small and the sustainability of effects in terms of gait was limited

There were no significant effects between groups in non-physical outcomes such as depression and fatigue

programme. GK wrote the first draft of the grant application and the present manuscript, and executed the data analyses. IGLvdP coordinated the FIT-Stroke trial and collaborated in designing the study, writing the study proposal and manuscript, and analysing the data. LEGW collected the data and was involved in the data analysis. EL collaborated in the funding procedure. All authors had full access to the data, take responsibility for the integrity of the data and the accuracy of the analysis. All authors reviewed the manuscript and approved the final version. GK is guarantor.

Funding: This study was funded by the Netherlands Organisation for Health Research and Development (ZonMw), No 80-82310-98-08303. Competing interests: All authors have completed the ICMJE uniform disclosure form at www.icmje.org/coi_disclosure.pdf (available on request from the corresponding author) and declare: no support from any organisation for the submitted work; no financial relationships with any organisations that might have an interest in the submitted work in the previous three years; no other relationships or activities that could appear to have influenced the submitted work.

Ethical approval: The FIT-Stroke protocol was approved by the medical ethics committee of the University Medical Centre Utrecht and all participating rehabilitation centres. All participants gave written informed consent.

Data sharing: No additional data available.

Lloyd-Jones D, Adams RJ, Brown TM, Carnethon M, Dai S, de Simone G, et al. Heart disease and stroke statistics-2010 update: a report from the American Heart Association. Circulation 2010;121:948-54.

2 Veerbeek JM, Kwakkel G, van Wegen EE, Ket JC, Heymans MW. Early prediction of outcome of activities of daily living after stroke: a systematic review. Stroke 2011:42:1482-8.

3 McKevitt C, Fudge N, Redfern J, Sheldenkar A, Crichton S, Rudd AR, et al. Self-reported long-term needs after stroke. Stroke 2011;42:1398-403.

4 Langhorne P, Bernhardt J, Kwakkel G. Stroke rehabilitation. Lancet 2011;377:1693-702.

5 Kwakkel G, van Peppen R, Wagenaar RC, Wood DS, Richards C, Ashburn A, et al. Effects of augmented exercise therapy time after stroke: a meta-analysis. Stroke 2004;35:2529-39.

6 French B, Leathley M, Sutton C, McAdam J, Thomas L, Forster A, et al. A systematic review of repetitive functional task practice with modelling of resource use, costs and effectiveness. Health Technol Assess 2008;12:1-117.

7 Wevers L, Van de Port, I, Vermue M, Mead G, Kwakkel G. Effects of task-oriented circuit class training on walking competency after stroke: a systematic review. Stroke 2009;40:2450-9.

8 English C, Hillier SL. Circuit class therapy for improving mobility after stroke. Cochrane Database Syst Rev 2010;7:CD007513.

9 Van de Port, I, Wevers L, Roelse H, van Kats L, Lindeman E, Kwakkel G. Cost-effectiveness of a structured progressive task-oriented circuit class training programme to enhance walking competency after stroke: the protocol of the FIT-Stroke trial. BMC Neurol 2009;9:43.
10 Scott NW, McPherson GC, Ramsay CR, Campbell MK. The method of minimization for allocation to clinical trials: a review. Control Clin Trials 2002;23:662-74.

11 Van Peppen RP, Kwakkel G, Wood-Dauphinee S, Hendriks HJ, Van der Wees PJ, Dekker $J$. The impact of physical therapy on functional outcomes after stroke: what's the evidence? Clin Rehabil 2004;18:833-62.

12 Duncan PW, Bode RK, Min LS, Perera S. Rasch analysis of a new stroke-specific outcome scale: the stroke impact scale. Arch Phys Med Rehabil 2003;84:950-63.

13 Duncan PW, Lai SM, Tyler D, Perera S, Reker DM, Studenski S. Evaluation of proxy responses to the stroke impact scale. Stroke 2002;33:2593-9.

14 Wevers LE, Kwakkel G, Van de Port, I. Is outdoor use of the six-minute walk test with a global positioning system in stroke patients' own neighbourhoods reproducible and valid? J Rehabil Med 2011;43:1027-31.

15 Twisk JW. Longitudinal data analysis. A comparison between generalized estimating equations and random coefficient analysis. Eur J Epidemiol 2004;19:769-76.

16 Gordon NF, Gulanick M, Costa F, Fletcher G. Franklin BA, Roth EJ, et al. Physical activity and exercise recommendations for stroke survivors: an American Heart Association scientific statement from the Council on Clinical Cardiology, Subcommittee on Exercise, Cardiac Rehabilitation, and Prevention; the Council on Cardiovascular Nursing; the Council on Nutrition, Physical Activity, and Metabolism; and the Stroke Council. Stroke 2004;35:1230-40.

17 Kollen B, Kwakkel G, Lindeman E. Hemiplegic gait after stroke: is measurement of maximum speed required? Arch Phys Med Rehabil 2006;87:358-63.

18 Tilson JK, Sullivan KJ, Cen SY, Rose DK, Koradia CH, Azen SP, et al. Meaningful gait speed improvement during the first 60 days poststroke: minimal clinically important difference. Phys Ther 2010;90:196-208.

19 Fulk GD, Echternach JL, Nof L, O'Sullivan S. Clinometric properties of the six-minute walk test in individuals undergoing rehabilitation poststroke. Physiother Theory Pract 2008;24:195-204

20 Dickstein R. Rehabilitation of gait speed after stroke: a critical review of intervention approaches. Neurorehabil Neural Repair 2008;22:649-60.

21 Van de Port, I, Kwakkel G, Lindeman E. Community ambulation in patients with chronic stroke: how is it related to gait speed? J Rehabil Med 2008;40:23-7.

22 Lord SE, McPherson K, McNaughton HK, Rochester L, Weatherall M. Community ambulation after stroke: how important and obtainable is it and what measures appear predictive? Arch Phys Med Rehabil 2004;85:234-9.

23 Schmid A, Duncan PW, Studenski S, Lai SM, Richards L, Perera S, Wu SS. Improvements in speed-based gait classifications are meaningful. Stroke 2007;38:2096-100.

24 Kwakkel G, Kollen B, Twisk J. Impact of time on improvement of outcome after stroke. Stroke 2006;37:2348-53.

25 Mead GE, Morley W, Campbell P, Greig CA, McMurdo M, Lawlor DA. Exercise for depression. Cochrane Database Syst Rev 2009;3:CD004366.

26 Zedlitz AM, Rietveld TC, Geurts AC, Fasotti L. Cognitive and graded activity training can alleviate persistent fatigue after stroke: a randomized, controlled trial. Stroke 2012;43:1046-51.

27 Outermans JC, Van Peppen RP, Wittink H, Takken T, Kwakkel G. Effects of a high-intensity task-oriented training on gait performance early after stroke: a pilot study. Clin Rehabil 2010;24:979-87.

\section{Accepted: 6 March 2012}

\section{Cite this as: BMJ 2012;344:e2672}

This is an open-access article distributed under the terms of the Creative Commons Attribution Non-commercial License, which permits use, distribution, and reproduction in any medium, provided the original work is properly cited, the use is non commercial and is otherwise in compliance with the license. See: http://creativecommons.org/licenses/bync/2.0/ and http://creativecommons.org/licenses/by-nc/2.0/legalcode. 


\section{Tables}

Table 1| Baseline characteristics of people with stroke allocated to task oriented circuit training intervention or usual care (control group). Values are means (SD) unless stated otherwise

\begin{tabular}{|c|c|c|c|}
\hline & Circuit training group $(n=126)$ & Control group $(n=124)$ & $P$ value \\
\hline \multicolumn{4}{|l|}{ Patients' characteristics } \\
\hline No $(\%)$ of men & $82(65)$ & $80(65)$ & 0.93 \\
\hline Age (years) & $56(10)$ & $58(10)$ & 0.32 \\
\hline \multicolumn{4}{|l|}{ No (\%) by type of stroke: } \\
\hline Ischaemic & $103(82)$ & $100(81)$ & \multirow[t]{2}{*}{0.82} \\
\hline Haemorrhagic & $23(18)$ & $24(19)$ & \\
\hline \multicolumn{4}{|l|}{ No (\%) by site of stroke: } \\
\hline Right hemisphere & $57(45)$ & $61(49)$ & \multirow[t]{4}{*}{0.53} \\
\hline Left hemisphere & $49(39)$ & $43(35)$ & \\
\hline Brainstem & $6(5)$ & $14(11)$ & \\
\hline Cerebellum & $14(11)$ & $6(5)$ & \\
\hline \multicolumn{4}{|l|}{ No (\%) by Bamford classification: } \\
\hline Total anterior cerebral infarct & $3(3)$ & $4(4)$ & \multirow[t]{4}{*}{0.91} \\
\hline Lacunar circulation infarct & $39(38)$ & $34(34)$ & \\
\hline Partial anterior cerebral infarct & $45(44)$ & $51(51)$ & \\
\hline Posterior circulation infarct & $16(15)$ & $11(11)$ & \\
\hline Time from stroke onset to randomisation (days) & $91(42)$ & $103(51)$ & 0.04 \\
\hline \multicolumn{4}{|l|}{ Primary outcome } \\
\hline Stroke impact scale 3.0 mobility $(0-100)$ & $80.9(13.04)$ & $77.8(15.00)$ & 0.08 \\
\hline \multicolumn{4}{|l|}{ Secondary outcome } \\
\hline \multicolumn{4}{|l|}{ Stroke impact scale 3.0: } \\
\hline Strength $(0-100)$ & $55.36(20.15)$ & $48.19(19.82)$ & $<0.01$ \\
\hline Memory/thinking (0-100) & $82.60(16.84)$ & $81.05(18.14)$ & 0.49 \\
\hline Emotion (0-100) & $82.28(13.42)$ & $82.84(13.76)$ & 0.74 \\
\hline Communication $(0-100)$ & $85.23(17.80)$ & $84.53(20.09)$ & 0.77 \\
\hline ADL/IADL $(0-100)$ & $71.25(15.42)$ & $68.99(15.43)$ & 0.25 \\
\hline Hand function $(0-100)$ & $48.33(36.55)$ & $41.81(34.41)$ & 0.15 \\
\hline Participation (0-100) & $65.58(21.49)$ & $67.94(20.18)$ & 0.37 \\
\hline Stroke recovery $(0-100)$ & $56.32(16.76)$ & $56.76(16.37)$ & 0.83 \\
\hline Fatigue severity scale (1-7) & $4.28(1.67)$ & $3.98(1.69)$ & 0.16 \\
\hline Falls efficacy scale $(0-130)$ & $98.98(19.77)$ & $95.59(18.90)$ & 0.17 \\
\hline \multicolumn{4}{|l|}{ Hospital anxiety and depression scale: } \\
\hline Depression $(0-21)$ & $5.10(3.60)$ & $4.40(3.23)$ & 0.11 \\
\hline Anxiety $(0-21)$ & $3.89(3.42)$ & $3.63(3.27)$ & 0.54 \\
\hline \multicolumn{4}{|l|}{ Nottingham extended ADL: } \\
\hline Mobility $(0-18)$ & $11.34(4.11)$ & $10.90(4.21)$ & 0.40 \\
\hline Kitchen (0-15) & $10.10(4.10)$ & $10.06(3.80)$ & 0.94 \\
\hline Domestic (0-15) & $5.15(4.73)$ & $4.53(3.93)$ & 0.26 \\
\hline Leisure $(0-18)$ & $7.99(2.97)$ & $7.31(2.87)$ & 0.07 \\
\hline Rivermead mobility index (0-15) & $12.67(1.58)$ & $12.35(2.00)$ & 0.16 \\
\hline Timed balance test $(0-5)$ & $3.65(1.05)$ & $3.46(1.11)$ & 0.16 \\
\hline \multicolumn{4}{|l|}{ Motricity index: } \\
\hline Arm $(0-100)$ & $62.73(26.48)$ & $57.97(26.23)$ & 0.15 \\
\hline $\operatorname{Leg}(0-100)$ & $71.23(19.85)$ & $64.98(20.06)$ & 0.01 \\
\hline
\end{tabular}


Table 1 (continued)

\begin{tabular}{lccc} 
& Circuit training group $(\mathbf{n = 1 2 6})$ & Control group $(\mathbf{n = 1 2 4})$ & P value \\
Time to accomplish (s) & $146(73)$ & $15(75)$ & 0.34 \\
\hline Omissions left $(0-20)^{*}$ & $1.25(2.34)$ & $1.37(3.05)$ & 0.73 \\
\hline Omissions right $(0-20)$ & $0.53(1.24)$ & $0.48(1.06)$ & 0.74 \\
\hline Functional ambulation (0-5) & $4.64(0.60)$ & $4.53(0.60)$ & 0.15 \\
\hline Comfortable walking speed (m/sec) & $0.9(0.3)$ & $0.8(0.4)$ & 0.09 \\
\hline Six minute walk test $(\mathrm{m})$ & $339(120)$ & $306(135)$ & 0.04 \\
\hline Timed up and go test (sec) & $15(10)$ & $18(19)$ & 0.11 \\
\hline Modified stairs test $(\mathrm{sec})^{*}$ & $19(11)$ & $20(10)$ & 0.38 \\
\hline
\end{tabular}

$A D L=$ activities of daily living; $I A D L=$ instrumental activities of daily living ${ }^{*} \mathrm{~N}=120$ v 121 . 
Table 2| Outcomes at 12 and 24 weeks for people with stroke randomised to task oriented circuit training intervention or usual care. Values for after treatment (12 weeks) and follow-up (24 weeks) are means (SD)

\begin{tabular}{|c|c|c|c|c|c|c|c|}
\hline & \multirow{2}{*}{\multicolumn{2}{|c|}{ Circuit training }} & \multirow{2}{*}{\multicolumn{2}{|c|}{ Usual physiotherapy }} & \multicolumn{3}{|c|}{ Multilevel regression analysis ${ }^{\star}, \beta$ (SE) } \\
\hline & & & & & \multirow[b]{2}{*}{$\begin{array}{c}\text { Time (baseline to } \\
24 \text { weeks) }\end{array}$} & \multicolumn{2}{|c|}{ Group xtime } \\
\hline & $\begin{array}{c}12 \text { weeks } \\
(n=125)\end{array}$ & $\begin{array}{c}24 \text { weeks } \\
(n=125)\end{array}$ & $\begin{array}{l}12 \text { weeks } \\
(n=117)\end{array}$ & $\begin{array}{l}\text { Follow-up } \\
(n=117)\end{array}$ & & $\begin{array}{l}\text { Baseline to } 12 \\
\text { weeks }\end{array}$ & 12 to 24 weeks \\
\hline \multicolumn{8}{|l|}{ Primary outcome } \\
\hline $\begin{array}{l}\text { Stroke impact scale } \\
\text { 3.0 mobility domain } \\
(0-100)\end{array}$ & $87.27(12.38)$ & $86.56(13.19)$ & $83.73(13.25)$ & $84.42(14.48)$ & $1.66(0.23), P<0.001$ & $-0.05(0.68), P=0.94$ & $-0.64(0.60), P=0.28$ \\
\hline \multicolumn{8}{|c|}{ Secondary outcomes, other domains of stroke impact scale $(0-100)$} \\
\hline Strength & $62.70(21.49)$ & $63.85(22.20)$ & $56.30(23.81)$ & $57.52(24.56)$ & $1.58(0.16), P<0.001$ & $-0.49(0.98), P=0.47$ & $0.00(0.81), P=1.0$ \\
\hline Memory and thinking & $85.49(16.75)$ & $87.23(15.92)$ & $87.12(15.32)$ & $87.08(15.92)$ & $2.18(0.55), P<0.001$ & $\begin{array}{c}-1.61(0.71) \\
P=0.024\end{array}$ & 0.79 (2.53), $P=0.76$ \\
\hline Mood and emotions & $81.91(14.81)$ & $82.02(14.87)$ & $81.86(14.25)$ & $82.18(16.02)$ & $0.00(0.58), P=1.00$ & $0.46(0.55), P=0.41$ & $0.44(0.54), P=0.414$ \\
\hline $\begin{array}{l}\text { Communication with } \\
\text { others }\end{array}$ & $85.97(18.84)$ & $86.74(16.67)$ & $87.09(17.14)$ & $87.32(17.23)$ & $\begin{array}{c}-0.67(0.23) \\
P<0.001\end{array}$ & $\begin{array}{c}-0.99(0.67) \\
P=0.140\end{array}$ & $0.27(0.68), P=0.69$ \\
\hline $\begin{array}{l}\text { ADLs during typical } \\
\text { day }\end{array}$ & $78.70(16.30)$ & $79.34(16.12)$ & $76.07(16.82)$ & $77.37(17.89)$ & 5.17.(0.44), $P<0.001$ & $-0.09(0.74), P=0.91$ & $-0.27(0.54), P=0.61$ \\
\hline $\begin{array}{l}\text { Ability to use most } \\
\text { affected hand }\end{array}$ & $58.60(37.36)$ & $60.64(36.55)$ & $52.56(37.94)$ & $55.51(37.94)$ & $3.48(0.35), P<0.001$ & 0.85 (1.06), $P=0.42$ & $0.52(0.77), P=0.50$ \\
\hline $\begin{array}{l}\text { Social participation in } \\
\text { ADLs }\end{array}$ & $70.90(20.78)$ & $71.78(21.18)$ & $73.05(18.25)$ & $75.74(16.44)$ & $1.56(0.64), P=0.007$ & $-0.08(1.21), P=0.95$ & $-0.84(1.10), P=0.45$ \\
\hline $\begin{array}{l}\text { Stroke recovery } \\
(0-100)\end{array}$ & $63.09(17.60)$ & $67.08(16.57)$ & $64.07(17.13)$ & $66.63(18.94)$ & $5.20(0.65), P<0.001$ & $0.98(2.00), P=0.62$ & $1.52(1.56), P=0.33$ \\
\hline $\begin{array}{l}\text { Fatigue severity } \\
\text { scale }(1-7)\end{array}$ & $4.25(1.74)$ & $4.23(1.72)$ & $4.22(1.66)$ & $4.03(1.67)$ & $0.01(0.07), P=0.87$ & $-0.25(0.19), P=0.19$ & $0.18(0.16), P=0.27$ \\
\hline $\begin{array}{l}\text { Falls efficacy scale } \\
(0-130)\end{array}$ & $102.70(21.11)$ & $104.45(20.38)$ & $102.15(20.68)$ & $104.03(22.19)$ & $\begin{array}{c}-4.36(0.69) \\
P<0.001\end{array}$ & $-3.25(1.99), P=0.10$ & $0.02(1.56), P=0.96$ \\
\hline \multicolumn{8}{|c|}{ Hospital anxiety and depression scale: } \\
\hline Depression (0-21) & $4.92(3.62)$ & $4.52(3.52)$ & $4.42(3.69)$ & $4.28(4.00)$ & $0.10(0.13), P=0.45$ & $-0.07(0.37), P=0.86$ & $-0.29(0.32), P=0.37$ \\
\hline Anxiety $(0-21)$ & $3.80(3.40)$ & $3.65(3.13)$ & $4.01(3.60)$ & $3.66(3.55)$ & $-0.02(0.13), P=0.88$ & $\begin{array}{c}-0.35(0.364) \\
P=0.34\end{array}$ & $0.18(0.30), P=0.55$ \\
\hline \multicolumn{8}{|c|}{ Nottingham extended ADL: } \\
\hline Mobility (0-18) & $13.90(3.77)$ & $14.17(3.75)$ & $12.97(4.31)$ & $13.62(4.14)$ & $1.40(0.17), P<0.001$ & $0.33(0.44), P=0.45$ & $-0.35(0.38), P=0.35$ \\
\hline Kitchen $(0-15)$ & $12.76(3.33)$ & $13.18(2.89)$ & $12.08(3.71)$ & $12.45(3.53)$ & $1.53(0.15), P<0.001$ & $0.67(0.40), P=0.09$ & $0.06(0.287), P=0.84$ \\
\hline Domestic (0-15) & $8.19(4.45)$ & $8.39(4.56)$ & $7.20(3.95)$ & $7.95(4.08)$ & $1.77(0.17), P<0.001$ & $0.23(0.46), P=0.62$ & $\begin{array}{c}-0.53(0.384), \\
P=0.17\end{array}$ \\
\hline Leisure $(0-18)$ & $9.45(3.16)$ & $10.50(3.79)$ & $9.46(2.90)$ & $10.39(3.60)$ & $1.53(0.15), P<0.001$ & $-0.74(0.37), P=0.04$ & $0.15(0.41), P=0.72$ \\
\hline $\begin{array}{l}\text { Rivermead mobility } \\
\text { index }(0-15)\end{array}$ & $13.47(1.44)$ & $13.50(1.42)$ & $12.82(1.90)$ & $13.03(1.82)$ & $0.37(0.05), P<0.001$ & $0.24(0.14), P=0.08$ & $\begin{array}{c}-0.15(0.116) \\
P=0.21\end{array}$ \\
\hline $\begin{array}{l}\text { Timed balance test } \\
(0-5)\end{array}$ & $4.06(1.02)$ & $3.82(1.45)$ & $3.74(1.06)$ & $3.36(1.52)$ & $-0.03(0.05), P=0.55$ & $0.09(0.11), P=0.08$ & $\begin{array}{c}0.12(0.133) \\
P=0.371\end{array}$ \\
\hline \multicolumn{8}{|l|}{ Motricity index: } \\
\hline Arm (0-100) & $68.30(25.12)$ & $69.88(24.44)$ & $62.20(27.21)$ & $65.04(27.49)$ & $3.77(0.47), P<0.001$ & 0.46 (1.25), $P=0.72$ & 1.14 (1.07), $P=0.29$ \\
\hline $\operatorname{Leg}(0-100)$ & $76.41(19.18)$ & $75.18(19.64)$ & $69.20(21.20)$ & $69.68(21.09)$ & $2.61(0.53), P<0.001$ & 0.69 (1.48), $P=0.64$ & $-1.81(1.28), P=0.16$ \\
\hline \multicolumn{8}{|l|}{ Letter cancellation task: } \\
\hline $\begin{array}{l}\text { Time to accomplish } \\
\text { (sec) }\end{array}$ & $148(64)$ & $151(69)$ & $146(89)$ & $149(86)$ & $-0.62(1.93), P=0.93$ & 1.09 (5.11), $P=0.84$ & -0.85 (5.11), $P=0.87$ \\
\hline Omissions (left) & $0.69(1.43)$ & $0.81(1.72)$ & $0.76(1.61)$ & $0.68(1.56)$ & $-0.15(0.07), P=0.03$ & $-0.27(0.19), P=0.16$ & $-0.06(0.01), P=0.53$ \\
\hline Omissions (right) & $0.44(1.06)$ & $0.47(1.19)$ & $0.41(1.12)$ & $0.57(1.13)$ & $\begin{array}{c}0.08(0.044) \\
P=0.088\end{array}$ & $-0.15(0.12), P=0.21$ & $-0.11(0.11), P=0.34$ \\
\hline $\begin{array}{l}\text { Functional } \\
\text { ambulation (0-5) }\end{array}$ & $4.87(0.36)$ & $4.89(0.36)$ & $4.74(0.55)$ & $4.78(0.49)$ & $0.13(0.02), P<0.001$ & $0.01(0.05), P=0.88$ & $-0.03(0.03), P=0.32$ \\
\hline $\begin{array}{l}\text { Comfortable walk test } \\
(\mathrm{m} / \mathrm{sec})\end{array}$ & $1.1(0.3)$ & $1.1(0.3)$ & $0.89(0.36)$ & $0.94(0.39)$ & $0.09(0.01), P<0.001$ & $0.09(0.02), P<0.001$ & $-0.04(0.02), P=0.04$ \\
\hline
\end{tabular}


Table 2 (continued)

\begin{tabular}{|c|c|c|c|c|c|c|c|}
\hline & \multirow{2}{*}{\multicolumn{2}{|c|}{ Circuit training }} & \multirow{2}{*}{\multicolumn{2}{|c|}{ Usual physiotherapy }} & \multicolumn{3}{|c|}{ Multilevel regression analysis ${ }^{\star}, \boldsymbol{\beta}$ (SE) } \\
\hline & & & & & \multirow[b]{2}{*}{$\begin{array}{c}\text { Time (baseline to } \\
24 \text { weeks) }\end{array}$} & \multicolumn{2}{|c|}{ Groupxtime } \\
\hline & $\begin{array}{c}12 \text { weeks } \\
(n=125)\end{array}$ & $\begin{array}{c}24 \text { weeks } \\
(n=125)\end{array}$ & $\begin{array}{c}12 \text { weeks } \\
(n=117)\end{array}$ & $\begin{array}{c}\text { Follow-up } \\
(\mathrm{n}=117)\end{array}$ & & $\begin{array}{c}\text { Baseline to } 12 \\
\text { weeks }\end{array}$ & 12 to 24 weeks \\
\hline $\begin{array}{l}\text { Six minute walk test } \\
\text { (m) }\end{array}$ & $412(117)$ & $416(118)$ & $354(145)$ & $366(151)$ & $\begin{array}{c}32.13(2.86) \\
P<0.001\end{array}$ & 20.00 (7.44), $P=0.01$ & -8.27 (4.45), $\mathrm{P}=0.06$ \\
\hline $\begin{array}{l}\text { Timed up and go test } \\
\text { (sec) }\end{array}$ & $11(7)$ & $11(8)$ & $15(16)$ & $14.60(13.79)$ & $\begin{array}{c}-1.76(0.28) \\
P<0.001\end{array}$ & $-0.65(0.73), P=0.38$ & -0.54 (0.38), $P=0.15$ \\
\hline $\begin{array}{l}\text { Modified stairs test } \\
\text { (comfortable) (sec) } \dagger\end{array}$ & $14(8)$ & $14(9)$ & $17(10)$ & $16.78(9.82)$ & $\begin{array}{c}-0.71(0.16) \\
P<0.001\end{array}$ & $-1.61(0.66), P=0.15$ & $-0.40(0.21), P=0.06$ \\
\hline
\end{tabular}

$A D L=$ activities of daily living.

* Regression coefficients of adjusted covariates of each analysis and regression coefficients for group available from corresponding author.

$\dagger \mathrm{N}=111$ in control and 120 in intervention group. 


\section{Figure}

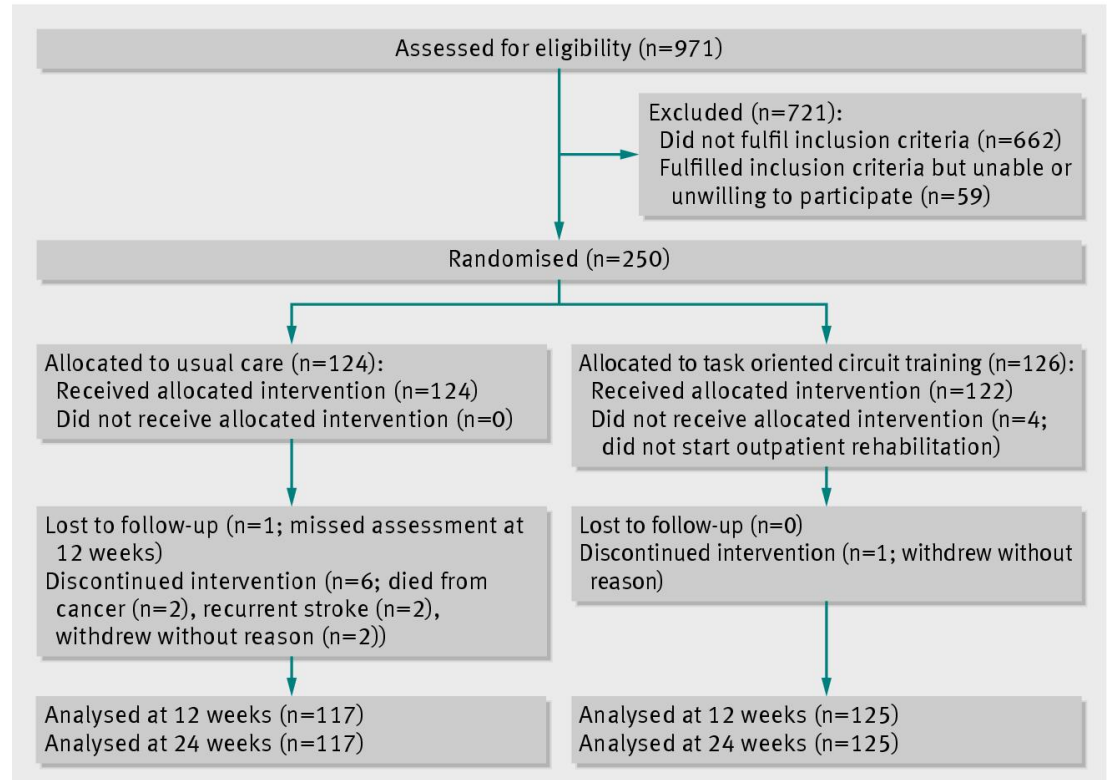

Flow of patients with stroke through study of circuit training compared with usual physiotherapy as part of rehabilitation 